\title{
Educação escolar indígena: a cultura e a história do Povo Borari na escola indígena de Alter do Chão.
}

\author{
Jecilaine Ferreira Silva ${ }^{1}$ \\ https://orcid.org/0000-0002-3960-5440 \\ Gilberto César Lopes Rodrigues ${ }^{2}$ \\ https://orcid.org/0000-0002-2408-0231
}

\section{Resumo}

O tema desta pesquisa é Educação Escolar Indígena. Analisamos a presença da história indígena, na disciplina de História, na escola indígena de Alter do Chão, em que examinamos a presença da história e cultura dos Borari no currículo escolar. A metodologia envolveu pesquisa exploratória, observação e coleta de dados através de levantamento documental, bibliográfica e de campo durante dois anos. Os resultados indicaram que a maioria dos professores segue o material didático enviado pelo MEC pois acham que devem segui-los, por fazer parte do currículo obrigatório que, segundo eles, dão mais visibilidade à história do sul e sudeste do país e ao Amazonas. Quando aborda o Pará são citados os povos bilíngues. No geral a escola aborda os temas indígenas na semana dos Povos Indígenas no mês de abril, em parceria com acadêmicos indígenas que realizam projetos voltados à valorização desses povos, quando é dado mais abrangência aos Borari.

Palavras-chave: Educação Escolar Indígena. Currículo. Borari de Alter do Chão. História. Disciplina de História.

\begin{abstract}
The theme of this research is Indigenous School Education. We analyze the presence of indigenous history in the discipline of History in the indigenous school of Alter do Chão. Where we examine the presence of Borari's history and culture in the school curriculum. The methodology involved exploratory research, observation and data collection through documentary, bibliographic and field surveys during two years. The results indicated that most of the teachers follow the didactic material sent by the MEC because, they think that they should follow them, being part of the compulsory curriculum, which, according to them, give more visibility to the history of the south and southeast of the country and the Amazon. When it comes to Pará, the bilingual peoples are mentioned. In general, the school addresses indigenous issues in the week of the Indigenous Peoples in April, in partnership with indigenous scholars who carry out projects aimed at enhancing these peoples, when it is given more scope to the Borari.
\end{abstract}

Keywords: Indigenous School Education. Curriculum. Borari from Alter do Chão. Story. Discipline of History.

\footnotetext{
Graduada em Pedagogia na Universidade Federal do Oeste do Pará em 2018. Email: jeciborari@gmail.com

Mestre na área de Filosofia da Mente, Epistemologia e Lógica. Doutor em Educação pela Unicamp. Professor no programa de Educação da Universidade Federal do Oeste do Pará. Email: gilbertocesar@gmail.com
} 
Introdução

O direito a uma educação escolar específica e diferenciada aos povos indígenas é garantido pela Constituição Federal de 1988 e pela Lei de Diretrizes e Bases da Educação Nacional - LDBEN, sendo que as Políticas de Educação Escolar Indígena são de competência do Ministério da Educação, cabendo aos estados e municípios sua execução para a garantia desses direitos. Com isso, reconheceu-se a pluralidade étnica do país como uma nação constituída por rica diversidade étnica e reconhecendo a esses povos o direito à manutenção de suas especificidades culturais, históricas e linguísticas, mudando a política governamental catequética e homogeneizadora em relação à educação escolar indígena até então vigente.

Ainda que os direitos à educação específica e diferenciada, o direito ao uso das línguas maternas serem regulamentados e garantidos aos povos indígenas, na Constituição Federal de 1988, na LDB de 1996, no RCNEI (Referencial Curricular Nacional para as Escolas Indígenas), no Parecer n 14/1999, na Resolução $n^{\circ} 3 / 1999$ do Conselho Nacional de Educação, Resolução nº 5, de 22 de junho de 2012, é comum encontrar, nas escolas indígenas, conteúdo e disciplinas ministradas do mesmo modo que é ensinado aos não indígenas, seguindo o mesmo currículo e livros didáticos das demais escolas do município. Muitos de seus professores e gestores não são indígenas, não reconhecem e nem valorizam a cultura indígena. São colocados e retirados, através de critérios políticos locais.

Além disso, vale também ressaltar que a Lei № 11.645, de 10 março de 2008, alterou a Lei nº 9.394, de 20 de dezembro de 1996, modificada pela Lei n ${ }^{\circ}$ 10.639, de 9 de janeiro de 2003, estabelecendo as diretrizes e bases da educação nacional, para que seja incluso no currículo oficial da rede de ensino a obrigatoriedade da temática "História e Cultura Afro-Brasileira e Indígena".

Diante disto, faz-se necessário mencionar a proposta de criação de uma base comum curricular, tendo início desde sua construção, em 2015, com a finalidade de estabelecer os conteúdos fundamentais a serem aprendidos por crianças e jovens durante a Educação Básica, que tem como principal objetivo, promover a equidade na educação, na medida em que garante aos alunos o acesso ao mesmo conteúdo nas escolas de todo o país, revertendo a histórica situação de exclusão social, destacando a importância de compreender a construção do conhecimento histórico, por meio dos processos de identificação, comparação, contextualização, interpretação e análise, focando na formação da identidade dos estudantes, considerando o tempo, a realidade e o espaço ao qual estão vinculados, articulando as competências gerais e específicas, previstas para a disciplina de História, a serem desenvolvidas no Ensino Fundamental.

Educação de qualidade é fundamental na transmissão de conhecimentos e na promoção da reflexão, despertando o senso crítico, a curiosidade e a participação dos alunos. Nesse processo cabe ao professor a função de transmitir o conteúdo que estimule a refletir e conduza a se transformar em um ser atuante na sua comunidade. Na escola Indígena Professor Antônio de Sousa Pedroso, foco de nossa pesquisa, mesmo sendo indígena, a maioria dos professores são não indígena, e poucos dão ênfase à história local. Os conteúdos dos livros da disciplina de História abrangem mais a região sul e sudeste, os quais muitas vezes não são incrementados com a realidade local por entenderem que não se deve mudar o currículo.

Para isso, partimos do entendimento conceitual de História, como a ciência que estuda os sujeitos no seu tempo e suas concepções. Com isso, a disciplina de História deveria ajudar o aluno a conhecer o passado e 
entender como aconteceu a formação das diversidades culturais e sociais entre os diversos tipos de lugares e povos, ressaltando a importância em transmitir conhecimentos históricos de um passado que lhe diz respeito, não tão distantes da atualidade, trazendo à tona as raízes da sua identidade, proporcionando o entendimento mais consistente da história de seu povo relacionando-a com a história de seu país e até mundial.

A questão motivadora envolveu entender o porquê de uma escola que se diz indígena, cravada no território Borari de Alter do Chão, local do aldeamento Borari administrado pelos jesuítas da Companhia de Jesus e atualmente requerente da demarcação da Terra Indígena Borari de Alter do Chão, não incorporar a história desse povo no ensino da disciplina de História.

O presente trabalho justifica-se pela importância da temática indígena, por se tratar de um pesquisador indígena, dentro de uma instituição indígena, para a formação histórica, social e cultural, tanto dos alunos como da comunidade, cujo interesse pessoal foi pesquisar a presença da cultura e a história do povo Borari na escola indígena de Alter do Chão, por meio da disciplina História, o qual surgiu a partir das observações feitas durante os estágios realizados na escola pois, mesmo sendo uma escola indígena, ainda é pouco abordado esse assunto no espaço escolar.

Trata-se de uma temática muito importante para que a cultura permaneça viva e prossiga com firmeza. Alter do Chão é historicamente conhecida como aldeia dos Borari, com vestígios concretos que possam confirmar essa ancestralidade, em locais sagrados ainda existentes na comunidade, como: Serra do Mocotó, Serra do Curucuruí, entre outros devidamente comprovados no Laudo Antropológico de Identificação e Delimitação da Terra Indígena Borari de Alter do Chão.

Além disso, possui relatos da história do Povo Borari desde as primeiras menções citadas por pesquisadores e cronistas em meados do século XVII, ligados ao longo do século XVIII, registros que constam informações gerais para entender o grupo indígena e o contexto sócio-histórico de sua ocupação tradicional e uma descrição etnográfica do povo e sua distribuição espacial.

Apesar dessas evidências, muitos dos professores ainda se sentem inseguros em tratar desse assunto em sala de aula, inclusive ao darem exemplos de conquistas indígenas, usam outros povos de outras regiões do país, como se não existissem na própria comunidade. Fato que, apesar de ser uma escola indígena, pouco se fala desta origem, a não ser nas datas próximas ou durante eventos como o aniversário de Alter do Chão, Dia do Índio, Festa Junina quando o tema é relacionado folcloricamente à cultura indígena e Çairé.

Essa pesquisa surgiu a partir da observação feita nos estágios realizados nesta escola, da falta de registros documentais sobre a origem e a cultura Borari, mesmo que em suas manifestações culturais sejam folclorizados, em alguns aspectos, encenam claramente a descendência e constituem uma ligação histórica nos termos mais presentes da identidade étnica, que retratam a origem dos índios Borari, mas, comunitários indígenas ainda vivem hoje com base nas características culturais, nos valores e na vivência dos antepassados indígenas, isso não é suficiente para manter nossos direitos consuetudinários respeitados.

Enquanto que para um grupo de profissionais não indígenas tão poucos sensíveis a esses direitos, e totalmente voltados para o capitalismo, tomando como base o turismo sem nenhum planejamento, deixam de lado os saberes milenares, esses direitos são criticados e menosprezados, e dificultam o real funcionamento da escola que deveria ser a referência no resgate e na valorização da cultura, apesar dos benefícios diferenciados já existentes na escola. 
Motivos esses que estimulam a necessidade de aprofundar na pesquisa da cultura do povo Borari, com intuito de produzir ferramentas concretas, que sirvam como fontes de informações e formações.

Como relevância científica, espera-se que os resultados alcançados sirvam como fontes concretas para futuras pesquisas na formação política e histórica dos povos indígenas do Baixo Tapajós, além de fomentar as discussões já existentes no meio acadêmico. Como relevância social, que venha contribuir para fundamentar o ensino da História do Povo Borari, servindo como base para a sua formação histórica, social e cultural, pois o fortalecimento desta identidade é necessário para a continuidade desta história e manter viva a cultura deste povo, que deu origem à população atual.

A preocupação com essa temática procedeu de estágios realizados nessa escola. Deles formulamos as seguintes inquietações: é repassado o conhecimento histórico do povo Borari nas diferentes atividades escolares neste nível de ensino? Os professores apenas seguem o livro enviado pelo MEC? Há temas indígenas no livro e nas aulas? De quais tipos? Como abordam os temas indígenas? Incrementam com a história Borari? As quais foram respondidas.

Através da observação, contato, entrevista e aplicação de questionário a professores que atuam no $1^{\circ}$ ao $5^{\circ}$ ano observamos que alguns professores trabalham a história do Povo Borari. Porém, apenas através das falas, repetindo o que foi ouvido dos mais velhos, mas sem muita firmeza e segurança no conteúdo. Os que não incluem essa história justificam que não há opções de fontes adequadas e que preferem seguir o que consta nos livros didáticos.

Assim, esta pesquisa tem como objetivo geral analisar a prática pedagógica dos professores da disciplina de História de $1^{\circ}$ ao $5^{\circ}$ ano da Escola Municipal de Ensino Fundamental Professor "Antônio de Sousa Pedroso" de Alter do Chão, examinando se na disciplina de História são trabalhadas a cultura e a história do povo Borari. E, como objetivo específico: identificar as práticas pedagógicas da disciplina de História aplicadas nas turmas de primeiro ao quinto ano, estimular a importância do ensino da cultura e história do povo Borari em sua própria escola, em seu contexto histórico e território, ao menos na disciplina de História, conhecer fontes concretas da história do Povo Borari por meio de pesquisas de campo para subsidiar sua inclusão no currículo escolar, estimular a construção de materiais didáticos, sobretudo que envolva o conhecimento tradicional dos mais velhos.

\section{Referencial teórico}

O direito a uma Educação Escolar diferenciada para os povos indígenas é assegurado pela Constituição Federal de 1988, pela Convenção 169 da Organização Internacional do Trabalho (OIT) sobre Povos Indígenas e Tribais, bem como por outros documentos nacionais e internacionais que visam assegurar o direito à educação como um direito humano e social.

Nos PCN de História e Geografia (BRASIL, 1997) são apresentados instrumentos aos professores e gestores, para embasá-los e orientá-los em termos de estratégias didático-pedagógicas que possibilitem aos alunos: questionar sua realidade e valorizar o patrimônio sociocultural.

Haja vista que o Referencial Curricular Nacional para as Escolas Indígenas (BRASIL, 1998) existe e pretende cumprir a tarefa de apresentar pela primeira vez em todo país, ideias básicas e sugestões de trabalho para o conjunto das áreas do conhecimento e para cada ciclo educacional das escolas indígenas inseridas no Ensino 
Fundamental, cujo objetivo é oferecer subsídios e orientações para elaboração de programas de Educação Escolar Indígena que atendam aos anseios e aos interesses das comunidades indígenas, levando em conta os princípios da pluralidade cultural e da igualdade entre todos os brasileiros, bem como, para a elaboração e produção de materiais didáticos e para formação de professores indígenas, assim torna-se fundamental seguir sua referência.

O Referencial Curricular Nacional para Escolas Indígenas (1998) foi publicado a partir das exigências da Lei de Diretrizes de Bases da Educação Nacional, que contempla a diferenciação das escolas indígenas. Demarca o avanço das conquistas dos diversos segmentos e movimentos que, desde a década 70, reorganizam os povos indígenas de todos os cantos do país em defesa da demarcação de suas terras, seguindo de todos os aspectos da vida dentro e fora das comunidades. Construído por profissionais qualificados de diversas áreas e representantes de diversas etnias indígenas, por meio de um amplo processo de encontros e seminários nacionais e regionais.

Bittencourt (2011) aponta a presença em algumas propostas pedagógicas de uma concepção de história do local ou de "história do lugar" que, de maneira geral, procura estabelecer relações entre o mais próximo, o vivido da criança, e a história nacional, regional e geral ou mundial. Entretanto, no caso das escolas indígenas, o próprio Referencial Curricular Nacional para as Escolas Indígenas (RCNEI, 1998, p. 23), reconhece que:

\footnotetext{
A escola não deve ser vista como o único lugar de aprendizado. Também a comunidade possui sua sabedoria para ser comunicada, transmitida e distribuída por seus membros; são valores e mecanismos da educação tradicional dos povos indígenas. Essas formas de educação tradicional podem e devem contribuir na formação de uma política e práticas educacionais adequadas, capazes de atender aos anseios, interesses e necessidades diárias da realidade atual. Tais conhecimentos não são incompatíveis com os conhecimentos da escola contemporânea.
}

Diante disto, ainda o RCNEI (1998, p. 23), nos orienta o seguinte: os Princípios da Educação Indígena entre os povos indígenas, a educação se assenta em princípios que lhes são próprios.

De acordo com os PCN de História e Geografia, (BRASIL, 1999, p. 49), o ensino e a aprendizagem estão voltados, inicialmente, para atividades em que os alunos possam compreender as semelhanças e as diferenças, as permanências e as transformações no modo de vida social, cultural e econômico de sua localidade, no presente e no passado, mediante a leitura de diferentes obras humanas. No entanto, o professor não deve se prender apenas no que consta nos livros didáticos como único meio de transmissão de conhecimentos.

A lei no 10639/2003 alterou a LDB para tornar obrigatório, nos currículos de educação básica brasileira, a inclusão da história e da cultura afro-brasileira. Sendo alterada em 2008, pela lei 11645/2008, que acrescenta a obrigatoriedade de se trabalhar nas escolas a história e a cultura dos povos indígenas. Ficando assim a nova redação do Art. 26-A: "Nos estabelecimentos de ensino fundamental e de ensino médio, públicos e privados, tornase obrigatório o estudo da história e cultura afro-brasileira e indígena.”

Para Rodrigues (2018), a conquista das escolas e a reelaboração a ela emprestada tem se tornado importante elemento aglutinador das sociedades indígenas brasileiras ganhando dimensões que tem superado a valorização, resgate e transmissão cultural. Isso também se dá na importância do que consta na Resolução CNE/CEB 5/2012, parágrafo único: "A escola indígena será criada em atendimento à reivindicação ou por iniciativa da comunidade interessada, ou com a anuência da mesma, respeitadas suas formas de representação".

Pode-se acrescentar a Base Nacional Comum Curricular (BNCC, 2017), por ser um documento de caráter normativo que define o conjunto orgânico e progressivo de aprendizagens essenciais que todos os alunos devem 
desenvolver ao longo das etapas e modalidades da Educação Básica, indicando os conhecimentos e competências que se espera que todos os estudantes desenvolvam ao longo da escolaridade, orientada pelos princípios éticos, políticos e estéticos traçados pela DCN, a BNCC vem somar aos propósitos que direcionam a educação brasileira para a formação humana integral e para a construção de uma sociedade justa, democrática e inclusiva.

Quanto à disciplina de História, a BNCC (2007, pg. 347) menciona que todo conhecimento sobre o passado é também um conhecimento do presente elaborado por distintos sujeitos, que o historiador indaga com vistas a identificar, analisar e compreender os significados de diferentes objetos, lugares, circunstâncias, temporalidades, movimentos de pessoas, coisas e saberes, que as perguntas e as elaborações de hipóteses variadas fundam, não apenas os marcos de memória, mas também as diversas formas narrativas, ambos expressão do tempo, do caráter social e da prática da produção do conhecimento histórico.

Diante disso, a BNCC (p. 348), expõe que, para se pensar o ensino de História, é fundamental considerar a utilização de diferentes fontes e tipos de documento capazes de facilitar a compreensão da relação tempo e espaço e das relações sociais que os geraram. Os registros e vestígios das mais diversas naturezas deixados pelos indivíduos carregam em si mesmos a experiência humana, as formas específicas de produção, consumo e circulação, tanto de objetos quanto de saberes, em que, nessa dimensão, o objeto histórico transforma-se em exercício, em laboratório da memória voltado para a produção de um saber próprio da história.

Cerri (1999, p.142) afirma que "a história quando ensinada serve para que os homens possam pensar historicamente, adicionando à sua reflexão os elementos que não estão presentes no imediato, mas sim no tempo longo, médio e curto. A história ensinada serve para ajudar a criar identidades, mas serve principalmente para que as pessoas se reconheçam como sujeitos, como parte também de um coletivo, conheçam suas possibilidades e limitações de ação na história. (...) para estimular a participação dos indivíduos nas práticas da cidadania". (CERRI, 1999, p.142).

Quanto à disciplina de História nas escolas indígenas, é preciso que haja uma reflexão entre os que nelas atuam, considerando as singularidades de cada povo, suas relações com a sociedade brasileira, com as tradições e a história cronológica dos indígenas, desde o começo do mundo até os dias atuais. São saberes que devem ser considerados nas propostas de estudo da História, visando conhecer e valorizar o povo indígena e sua cultura, dáse a importância em ensinar a cultura e a história do Povo Borari nas disciplinas de história, principalmente nas turmas de $1^{\circ}$ ao $5^{\circ}$ ano.

O RCNEI (1998, p 22), diz que o Brasil é uma nação constituída por grande variedade de grupos étnicos, com histórias, saberes, culturas e, na maioria das situações, línguas próprias. Tal diversidade sociocultural é riqueza que deve ser preservada. Cada povo indígena que vive hoje no Brasil é dono de universos culturais próprios. Sua variedade e sua originalidade são um patrimônio importante não apenas para eles próprios e para o Brasil, mas, de fato, para toda a humanidade.

Através das lutas por direitos a escolas diferenciadas e específicas, reivindicadas pelos movimentos de lideranças indígenas de várias etnias do país, teve como marco histórico a Constituição Federal de 1988 e seus incrementos nas leis e nos documentos oficiais que regulamentam a política de educação, como a Lei e Diretrizes de Bases da Educação Brasileira-LDB, n 9394/96, os Parâmetros Curriculares Nacionais (PCN), Plano Nacional de Educação-PNE e o Referencial Curricular Nacional para Escolas Indígenas-RCNEI.

Apesar de documentos como o Plano Nacional de Educação (2001) privilegiarem o profissional indígena com formação específica, ainda são inúmeros os professores não indígenas que atuam nas escolas indígenas, assim 
como acontece em Alter do Chão, onde a articulação entre conhecimento tradicional e o conhecimento universal, é um grande desafio. Avaliando o Plano Nacional de Educação, observa-se o formato como a União trata a questão da educação escolar indígena. Muitas vezes não há quem queira assumir essa responsabilidade, ora delega aos Estados e Municípios, ora atribui a competência à União.

Os indígenas necessitam da escola para dominarem instrumentos de luta e de resistência política e social. Também se faz necessário adquirir conhecimentos que assegurem sua autonomia diante da sociedade brasileira, incluir conteúdos que contribuam para a construção e consolidação da história das lutas políticas dos povos nativos pela reivindicação do direito à diversidade étnica e cultural e à cidadania na sociedade brasileira, mantendo-as vivas e significativas perpetuando gerações cada vez mais fortes e resistentes.

Nota-se a importância de trabalhar a formação histórica cultural e social do aluno, tendo como ponto de partida o estudo da história local, em que, por meio desta seja possível conhecer suas raízes, construir e valorizar sua própria identidade. É de responsabilidade do educador ensinar uma História que faça parte do dia a dia do aluno, para não privar seus próprios conhecimentos, valorizando suas memórias histórica e cultural, pois somente assim o ensino da História do Povo Borari terá continuação com outra visão, outro significado e sua aprendizagem será reconhecida e respeitada por todos.

\section{Materiais e métodos}

A metodologia da pesquisa envolveu levantamento acerca dos temas e assuntos abordados na disciplina de História das turmas de $1^{\circ}$ ao $5^{\circ}$ ano, comparando com as possíveis contribuições do Referencial Curricular Nacional do Ensino Fundamental para o ensino de História à luz dos Parâmetros Curriculares Nacionais - volume 5: História e Geografia (BRASIL, 1997) e do Referencial Curricular Nacional para as Escolas Indígenas (BRASIL, 1998). Realizamos a caracterização da unidade escolar, professores e dos alunos. Por fim examinamos quais os conteúdos disponíveis atualmente, seguido de uma pesquisa sobre quais fontes existem para que possam obter informações concretas referentes ao ensino da história do povo Borari.

Com intuito de coletar informações para andamentos da pesquisa, houve a aproximação na escola, iniciando com uma conversa formal com o diretor, um bibliotecário e os nove professores da disciplina de História, do $1^{\circ}$ ao $5^{\circ}$ ano. Em que foi falado, na visão de cada um, a importância da disciplina de História nas escolas; O que é ensinado na escola Borari? É ensinada a história indígena? É ensinada a história de Alter do chão? É ensinada especificamente a história dos Borari? Ficando marcado para que cada um pudesse me atender na sequência, de acordo com a disponibilidade dos mesmos, em suas respectivas salas.

Para a realização da entrevista, foi aplicado um questionário, o qual teve com o objetivo saber se a Cultura e a História do Povo Borari estão presentes na disciplina de História da Escola Indígena de Alter do Chão. Sendo que foi preciso ter cuidados minuciosos com os professores, pois, o mais difícil é tratar de um tema que está no dia a dia da escola, mas não é aceito por grande parte de professores, apesar de estarem por tanto tempo na escola indígena, não há interesse em compreender a fundo de que se trata. E que Educação Escolar Indígena está longe de acontecer em uma escola indígena, gerenciada pelo governo, e aceita pela gestão que tão 'pouco se interessa em fazer Educação Escolar Indígena por falta de informação. 
Haja vista que, o ensino da História do Povo Borari nas aulas da disciplina de História, servirá como base para a formação histórica, social e cultural, contribuindo assim para o fortalecimento dessa identidade, na esperança de dar continuidade à história e manter viva a cultura deste povo a qual deu origem à população atual, que conquistou o direito a uma Escola Indígena em 2006 e deve, através dela, ampliar conquistas no campo dos direitos territoriais, valorização da cultura, o uso das pinturas corporais, cujo o seu grafismo representa a força e a resistência, como proteção diante das dificuldades enfrentadas no seu dia a dia, pois trata-se de um povo forte e guerreiro, mesmo que passivo, possui suas formas próprias de lutas para preservar sua identidade.

\section{Caracterização da área}

Alter do Chão era habitada pelos indígenas Borari, conforme relatos da história do Povo Borari. Desde as primeiras menções citadas por pesquisadores e cronistas em meados do século XVII, com registros que constam informações gerais para entender o grupo indígena e o contexto sócio-histórico de sua ocupação tradicional e uma descrição etnográfica do povo e sua distribuição espacial, ainda se tem marcas dessa aldeia devido à existência de diversos locais com grande quantidade de vestígios. Isso fez surgir o movimento indígena, ou seja, moradores nativos que reivindicam a demarcação dessas terras por direitos ancestrais, visto que na comunidade há uma grande preocupação em valorizar a identidade e a cultura Borari.

Residem em Alter do Chão aproximadamente 7.000 habitantes fixos (SEMSA, 2017), divididos em 582 famílias indígenas (SESAI, 2018), além de mais pessoas que circulam no decorrer do ano, em que as atividades socioeconômicas estão voltadas para o turismo. Quanto ao movimento indígena de Alter do Chão, trata-se de um processo recente que está em formação e cujos mecanismos de mobilização, tomada de decisões, articulação com instâncias e formação de alianças e parcerias encontram-se em desenvolvimento e precisam ser fortalecidos.

A escola Municipal de Ensino Fundamental Professor Antônio de Sousa Pedroso está localizada na vila de Alter do Chão, rua Pedro Teixeira, No 340, Região do Tapajós, Município de Santarém, estado do Pará. Foi criada em 30 de maio de1985, pelo decreto $\mathrm{n}^{\mathrm{o}} 772 / 85$ - DAD.

Sua inauguração deu-se em $1^{\circ}$ de junho de 1985, funcionando inicialmente com quatro salas de aula, 49 alunos de $5^{\mathrm{a}}$ série do Ensino Fundamental e seis professoras. Tendo sua primeira turma concluído a $8^{\mathrm{a}}$ série no dia 26 de janeiro de 1989, com 22 alunos e como paraninfa a professora Maria Olívia Araújo Sousa, usando o salão paroquial da comunidade para o evento. (PPP-2015)

A partir de junho de 2006, a coordenação da Secretaria Municipal de Educação (SEMED) comunicou à direção da referida escola que a mesma estava contemplada para funcionar como Educação Indígena junto ao MEC, pela coordenadora de Educação Escolar Indígena na época, a Antropóloga Iza Tapuia, pois a comunidade sempre buscou resgatar sua identidade e autorreconhecimento de sua etnia Borari, valorizando a cultura de seu povo. Visto que a escolarização representa para esses indígenas a possibilidade de organização de frentes de luta na defesa de seu território, bem como, a afirmação de políticas públicas mais justas visando à cidadania para seu povo.

Há na escola o Conselho Escolar, que contribui nas questões burocráticas, pedagógicas e administrativas. Auxilia a direção da escola a desenvolver um trabalho integrado com a comunidade escolar, sendo que as reuniões 
acontecem bimestralmente ou quando há alguma eventualidade, sempre com o objetivo de melhorar a qualidade do ensino e aprendizagem. Diante disso, procuram desenvolver um ensino de qualidade em busca de uma aprendizagem eficaz na formação de cidadãos conscientes, acreditando que a educação é a solução para a maioria das mazelas de nossa sociedade.

Atualmente, possuem 687 alunos matriculados, subdivididos em educação infantil, ensino fundamental I e II e EJA I e II, duas turmas anexas à Escola Dom Macedo Costa. São ao todo 57 servidores divididos em administração, técnicos e apoio. Tem uma estrutura física boa, por ser um espaço plano de fácil acesso, mas ainda insuficiente para o atendimento adequado. Possui 01 diretoria, 01 secretaria, 03 salas de educação infantil, 15 salas de ensino fundamental, 01 sala de professores, 01 biblioteca com TV e vídeo, 01 sala de informática, 01 auditório (maloca), 01 cozinha, 01 refeitório, 01 quadra de esportes, banheiros para funcionários, área de esportes, 02 dispensas, 02 banheiros para educação infantil, 02 banheiros para os demais níveis.

\section{Resultados e discussões}

Quando as leis brasileiras se referem à autonomia das comunidades indígenas e à importância das mesmas na elaboração dos projetos pedagógicos, possibilitam a criação de escolas indígenas, segundo suas formas de organização e seus processos próprios de aprendizagem. No caso de Alter do Chão, como e o que deve ser transitado no espaço escolar é decidido apenas pela equipe gestora, segundo suas necessidades internas, preparação para o mercado de trabalho, novas tecnologias, vestibulares, privilegiando a quantidade em detrimento da qualidade. Essas são demandas atuais da globalização, pouco se dá espaço para o que a comunidade tem de valor cultural.

Após a reformulação do PPP em 2015, o mesmo possui 14 objetivos específicos, onde se destacam três deles voltados para a questão indígena, que mesmo constando no PPP, não são vivenciados na prática, sendo: cultivar a memória coletiva do povo brasileiro, valorizando a dimensão pedagógica e política da história local e global; manter vivo o patrimônio cultural do povo Borari e de outras etnias; revitalizar a linguagem indígena nheengatu e os saberes étnicos culturais, através do ensino notório saber.

Diante disso, observa-se que apesar de estar incluso, tal objetivo não funciona na prática. O que se entende é que até mesmo o PPP é pouco utilizado, pode-se observar que a nova gestão não tinha conhecimento do conteúdo do PPP, assim como a maioria dos professores nunca tinham visto tal documento.

Os objetivos da educação escolar indígena devem ser discutidos e definidos pelos próprios povos, dependendo de seus anseios e necessidades, mas o importante é que tenham participação nas decisões e ações de suas escolas como instrumentos na construção de seu futuro. No caso da escola indígena de Alter do Chão, muitas situações não chegam se quer ao conhecimento do Cacique ou de qualquer outra liderança indígena, a não ser se for um caso que dependa unicamente do movimento.

Após o contato com a direção da escola, uma conversa com o diretor, em seguida com bibliotecário e com os professores de História, seguido de visita à sala dos mesmos no momento de aula, em que foram coletadas as informações precisas. Iniciando uma fala sobre seus respetivos Planos de Cursos e Plano de Aula, pois cada professor faz o seu, sendo que, apesar de afirmarem que fazem planos de aula, apenas dois dos professores mostraram seu plano de aula. 
Em conversa com o gestor, quando se questionou a importância de ensinar a cultura Borari na disciplina de História, ele afirmou que é de fundamental importância para que o aluno conheça a história não só do Brasil, mundialmente, mas principalmente do lugar onde vive. Informou que todos os professores são formados na área, e buscam realmente ensinar a disciplina levando em conta a história local e regional. Porém, conforme discutem o plano de curso na semana pedagógica realizada no início de cada ano letivo, guiando a grade curricular, ressaltou não poder se afastar desse currículo, mas busca trabalhar a questão local, em que cada professor possui seu método de pesquisa.

Segundo o gestor, há na escola dois professores por turmas de $1^{\circ}$ ao $5^{\circ}$ ano, com horários alternados, apenas no segundo ano um mesmo professor atende as duas turmas, em horários diferentes. O que totaliza nove (09) professores, regentes, dessas turmas que trabalham com todas as disciplinas. Já do $7^{\circ}$ ao $9^{\circ}$ ano há 3 professores específicos das disciplinas de História que atendem 17 turmas. O planejamento dessas aulas é feito na semana pedagógica, discute-se o plano de curso dos professores, para orientar que as aulas sejam planejadas em conjunto conforme o ano. Mas, foi relatado ainda pelo gestor, que têm professores que se isolam e planejam individualmente.

Em conversa com o bibliotecário, observou-se que a situação dos livros didáticos é precária. A escola não recebe livros suficientes para a quantidade de alunos matriculados, o que dificulta mais ainda o trabalho do professor, apesar de serem feitos pedidos junto à Semed, não são atendidos. Em uma turma de 25 alunos, em média há de 15 a 18 livros, e para atender toda a turma é preciso fazer um rodízio, tornando-se difícil para as crianças.

Os professores da disciplina de História, assim como os das demais disciplinas, escolhem os livros para trabalharem no ano seguinte. Muitas vezes, ao utilizarem não lhes dão muita opção, principalmente quando se trata da História da região e, infelizmente, os professores seguem o que vem realmente nos livros, pois não disponibilizam de acervos mais voltados para a história local, mas acreditam que a academia tenha planos para mudar essa realidade.

Diante do que foi exposto, é possível perceber que muitos professores, mesmo trabalhando em uma escola indígena, não dão muita importância ao fato de ser uma escola indígena. Se não consta nada no livro sobre a história local, não procuram o tema em outras fontes, como é feito com os conteúdos globais. Além disso, a história dos povos indígenas que consta nos livros não é trazida para a realidade local. Nos PCN dão essa abertura, mas preferem seguir à risca apenas o que consta nos livros por entenderem que não pode fugir do currículo.

Observou que tanto o PPP quanto o conteúdo programático precisam ser reformulados para atender as necessidades de uma escola indígena, acompanhado de formações para os professores, pois precisam entender que um currículo, o conteúdo programático e o que consta nos livros didáticos não são prontos e acabados. Uma vez trazendo esses conteúdos para a realidade local não estão ferindo o sistema educacional, mas buscando uma melhor forma de transmitir o contexto histórico, social e cultural mais próximo do aluno.

Ao finalizar as entrevistas, foi perceptível que há professores bastante informados com conteúdo globais, mas não conhecem a história local, ou não consideram tão importante a História e a origem do povo que existe atualmente na comunidade. Com isso, cabe uma reflexão: "Isso advém de informação inexistente, ou não querem que exista? Onde encontrar? Por que não incrementar os conteúdos do livro com a história da cultura local?”. O ensino crítico da disciplina de História pode levar à compreensão do que é ser cidadão, desde que não seja tão somente um reprodutor do conhecimento que os livros didáticos apresentam. 
As fontes também são importantes para que a construção da História seja vista como um campo de conhecimento em que se valoriza a pesquisa documental, em registros e testemunhos sobre outras épocas. O objetivo é verificar que os fatos realmente aconteceram e que ocorreram em determinada data e contexto.

Apesar de o texto escrito ter se transformado como principal documento utilizado pelos estudiosos da História, sendo entendido como testemunho, "prova" de que os acontecimentos do passado aconteceram, realmente, da "maneira correta", acreditando-se que só os povos que haviam desenvolvido a escrita eram povos com História. Isso dificultou a realização de pesquisas sobre as sociedades que não deixaram registros escritos e o estudo de outras fontes de informação que favorecessem a compreensão do modo de viver, representar e comunicar dessas sociedades. Mas, isso tende a mudar, pois todos os povos têm História.

A entrevista foi positiva para saber o que realmente acontece na prática com a Cultura e a História indígena de uma comunidade que descende de uma população indígena, com vestígios concretos. Existe uma escola indígena de direito, apesar de não ser de fato, isso faz com que gestor e professores não levem em conta a presença de indígenas no contexto social e até mesmo histórico da escola. Observou-se que quando se trata da questão indígena é muito vago entre os professores, pois eles ainda veem os indígenas como apenas aqueles aldeados, isolados, sem roupas e sem tecnologias, longe da globalização.

Muitos professores não incentivam seus alunos que estão em uma escola indígena, por estarem em uma comunidade indígena, por serem descendentes do Povo Borari como consta em relatos históricos e por haver vestígios concretos da presença desse povo que formou nossos antepassados. Buscam apenas informações que estão nos livros didáticos como verdadeiras. Sem trazer para a realidade do aluno o porquê de estarem aqui, como surgiu, o porquê dos seus hábitos e costumes. Muitos alunos trazem consigo de casa essas informações, alguns professores tentam mudar seu entendimento para que prevaleça apenas o que consta nos livros, longe da realidade local.

A educação escolar indígena não serve para que os índios saiam de suas aldeias e se integrem na vida do homem branco, mas sim para que possam se comunicar entre si e para fora das aldeias, defendendo seu modo de vida e como forma de preservação de suas tradições, como acontece nas universidades. A educação está relacionada às mudanças de sujeitos e mundos em algo melhor, de acordo com cada visão do que é "melhor".

Com isso, pode-se observar que muitos professores se retraem ao falar de suas práticas docentes com acadêmicos, por pensarem que os mesmos estão ali para os observarem e uma possível substituição quando formados, pois, em meio às conversas sempre reforçam que para ser um docente precisa pagar pra trabalhar, ou então buscar as "grandes cidades" para um bom emprego remunerado, como se o mais importante nas escolas fossem realmente o salário para se manter e não a busca por uma educação de qualidade, que no caso de uma escola indígena, faça uma educação escolar indígena realmente diferenciada.

Provavelmente a ideia mais forte que tenha se firmado ao longo desse período seja a de que a escola pode ser apropriada pelos povos indígenas, que podem dar a ela um novo significado e um novo sentido, capaz de promover a integração dos indígenas à comunhão nacional, por meio do aprendizado do idioma português e pelo progressivo abandono de suas línguas nativas e práticas culturais. Assim, na escola pesquisada, pouco se valoriza o notório saber e a língua nheengatu que está inserida como disciplina não obrigatória.

As demandas por escolas indígenas nas comunidades, não é por qualquer tipo de escola, mas por uma escola gerida por representantes das comunidades indígenas, que permitam acesso a saberes universais, que sirva de ponto 
de referência dos processos de valorização, resgate e transmissão cultural, sobretudo na disciplina de História de uma escola cravada no interior de uma pretensa Terra Indígena e de um povo, cuja parte, tem orgulho de dizer que é Borari.

\section{Considerações finais}

A Cultura e a história do povo Borari na Escola Indígena de Alter do Chão foi o tema pesquisado. Partimos da questão: a cultura e a história dos Borari estão presentes na disciplina de História da Escola Indígena de Alter do Chão? Para a coleta de informações foram feitas várias visitas na escola, em eventos, estágios e reuniões, desde $r \cdot 10$, como observadora. Finalizando com a aplicação de um questionário aos professores de $1^{\circ}$ ao $5^{\circ}$ ano, conversa com gestor e bibliotecário, além de observação em salas de aula.

No início houve-se desavenças, contradições de opiniões com professores que pensavam que eu estava ali para ocupar seus espaços. No final de 2017 para o início de 2018, quando se definiu o tema a ser pesquisado, ao retornar à escola, fui bem recebida, tanto pelo gestor, quanto por professores e demais funcionários. A partir desse período as visitas foram mais constantes, porém, a equipe escolar estava mais próxima, disposta a ajudar e me envolvi diretamente nas atividades da escola. Tive oportunidades de observar a realidade da escola, assim como as práticas pedagógicas de cada professor.

Ao final, as conversas foram mais harmoniosas, muitos professores passaram a entender melhor a importância da presença constante da história e da cultura Borari no dia a dia da escola. E que é preciso caminhar junto com a comunidade para que a mesma seja realmente uma escola indígena de fato.

Como resultado da entrevista, nota-se que está longe de tornar realidade a escola pesquisada ser uma escola indígena na prática. Pois, as pessoas, apesar de estarem inseridas diariamente em uma escola indígena, a maioria prefere apenas manter seus empregos, seguindo o que a SEMED impõe. Isso acontece porque há uma gestão pouco preocupada em atender as necessidades da população indígena como diferenciadas.

O que é mais visível é o apadrinhamento político que existe dentro da escola com a equipe de profissionais que formam a equipe de funcionários, pois, para preservar seus empregos são submissos a qualquer ordem dos partidos políticos regentes, em que o próprio gestor se afirma um “índio" com cabeça de branco. Mesmo com tudo isso, pode haver uma esperança de mudanças e autonomia, visando os novos profissionais que estão se formando com uma nova visão, e politicamente formados.

Durante a pesquisa, observou-se que muitos professores, mesmo estando há algum tempo morando em Alter do Chão e trabalhando na escola, não aceitam a ideia de ser uma aldeia, nem concordam que a escola tenha sido incluída como escola indígena. Motivos esses que fazem com que não compartilhem e nem deem continuidade à história da comunidade como descendentes do Povo Borari. Apesar de ser um assunto bastante discutido atualmente, não se aprofundam na questão, pois preferem ficar alienados, parece que se sentem ameaçados, até mesmo quando o tema é Educação Escolar Indígena e quando se trata de Direitos Indígenas, mas usam desses direitos para permanecerem na escola.

Por meio da pesquisa realizada foi possível conhecer e identificar as metodologias e as práticas pedagógicas que são utilizadas pelos professores no ensino de História das turmas de $1^{\circ}$ ao 5 ano do Ensino Fundamental da 
escola indígena Borari. Percebe-se que há necessidade de uma reflexão dos docentes, ou seja, ser repensada sua forma de ministrar aulas, pois eles ainda estão muito presos às metodologias tradicionais, longe de despertar o interesse e a motivação dos alunos, tornando-os muitas vezes alheios diante dos conteúdos abordados na disciplina. Enquanto que, na realidade, seria mais prazeroso dar mais importância à aproximação daquilo que é ensinado com a realidade vivida pelos alunos, levando em conta o contexto histórico social e cultural local existentes, adequando às abordagens feitas em sala de aula.

Na visão de cada entrevistado, notou-se que as respostas para as questões evidenciaram que é ensinada a história indígena muito superficial, mais voltada para os povos bilíngues e de pouco contato com a sociedade, em que apenas alguns professores relacionam com a realidade local. A história de Alter do Chão tem menções próximas ao aniversário da vila e ao Sairé, alguns temas voltados para o período colonial. Alegam ainda que os livros só possuem informações vagas, que precisam recorrer a livros antigos e a outras fontes como internet, que ainda é precária na comunidade, que o sistema não dá condições necessárias para executarem suas práticas pedagógicas, o que demonstra pouco movimento dos docentes no sentido de superar suas próprias falhas conceituais e pouca desenvoltura para pesquisas próprias.

Quanto ao domínio da história dos Borari, alguns professores sentem-se inseguros em falar, outros não pesquisam a fundo, mesmo estando incluídos em uma escola indígena, não aceitam dar mais consistência ao tema. Muitos reconhecem Alter do Chão como a antiga aldeia dos Borari. Alguns avançam no entendimento que persistem e resistem como Povos Indígenas do Baixo Tapajós. Mas, a maior parte não respeita a população indígena de hoje que fez com que a escola fosse indígena não para atender os direitos consuetudinários, mas para benefícios individualistas e mesquinhos.

Para finalizar, é preciso que haja mais interesse em buscar fontes existentes para enriquecer os conteúdos que constam nos livros da Disciplina de História, pois assim como o Currículo, servem como ferramentas norteadoras nas práticas pedagógicas. E esse interesse particular deve vir acompanhado de um envolvimento coletivo dos agentes e instituições, principalmente do Sistema Educacional que deve dar mais condições às escolas e aos professores, seguido do município que possa se interessar mais pela educação escolar indígena e buscar meios para estruturar as escolas, juntando-se com demais instituições, buscando realmente a consolidação territorial, cultural e histórica dos Borari de Alter do Chão. Surara!

\section{Referências}

BITTENCOURT, Circe. Ensino de História: fundamentos e métodos. 4ed. São Paulo: Cortez, 2011.

BRASIL. Lei n. 11.645, de 10 de março de 2008. Altera a Lei no 9.394, de 20 de dezembro de 1996, modificada pela Lei no 10.639, de 9 de janeiro de 2003.

BRASIL. Ministério da Educação. Base Nacional Comum Curricular. Disponível em: http:// basenacionalcomum.mec.gov.br/\#/site/relatoriosanaliticos. Acesso em: 23 mar. 2017.

BRASIL. Ministério da Educação. Conselho nacional de educação. Câmara de educação básica.

Resolução CNE/CEB 5/2012. Diário Oficial da União, Brasília, 25 de junho de 2012, Seção 1, p. 7. 
BRASIL. Ministério da Educação e da Cultura. Secretaria da Educação Básica. Parâmetros

Curriculares Nacionais (PCN): História e Geografia. Brasília: MEC/SEF, 1997.

BRASIL. Ministério da Justiça. Relatório circunstanciado de identificação e delimitação terra indígena Borari de Alter do Chão. Portaria Funai/MJ n ${ }^{\circ}$ 776, de 04 de julho de 2008. Antropólogocoordenador: Ricardo Neves R. Pereira. Brasília, dez. 2009.

BRASIL. Referencial Curricular Nacional para as Escolas Indígenas/Ministério da Educação e do Desporto, Secretaria de Educação Fundamental. - Brasília: MEC/SEF, 1998.

CERRI, Luis Fernando. Os objetivos do ensino de história. Hist. Ensino, Londrina, v. 5, p. 137-146, out. 1999.

PROJETO POLÍTICO PEDAGÓGICO 2015. escolaborari.blogspot.com. empaspalter@gmail.com.

RODRIGUES, Gilberto César Lopes. Quando a escola é uma flecha. Educação Escolar Indígena e Territorialização na Amazônia. Revista Exitus. Santarém/PA, v. 8, n. 3, p. 396 - 422, set/dez 2018.

SILVA, Jecilaine. Pesquisa de Campo. Santarém - PA: UFOPA, 2018.

Recebido em: 04/02/2019

Aprovado em: 13/09/2019 